\title{
Our Commitment to Open Access and to Integrity in Scientific Publication
}

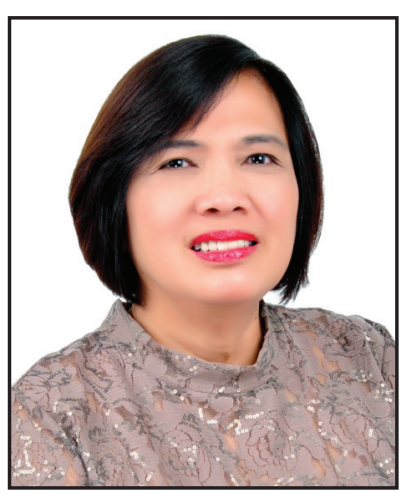

We are happy to announce our journal website's recent shift to online hosting under the Public Knowledge Project (PKP), a reinforcement of our commitment to open access and to integrity in scientific publication.

The Budapest Open Access Initiative (BOAI) in 2002 defines Open Access as "free availability on the public internet without financial, legal, or technical barriers other than those for access to the internet." As a 100\% Open Access journal, the JAFES provides all scholarly content free of charge to everyone. It relies on the continued support of AFES member societies to subsidize its operations, in the process eliminating the need to levy article processing charges or APC's to authors for now. As a return service, almost all our journal advertisements are complimentary, a free service that JAFES provides to AFES member societies who wish to promote events or make announcements. A very small percentage of advertisements do contribute to journal income.

For non-profit, open-access scholarly journals in general, the situation is not without difficulty. Processing high quality, original, peer-reviewed content, improving visibility and search ability in the internet, and ensuring security of intellectual property, do entail significant resources.

JAFES does not sell the journal or its services to gain income, unlike "predatory" and "double dip" open-access journals. Predatory journals provide faster and easier way of publishing usually without legitimate peer review while charging APCs usually in very significant amounts. Double dip journals not only charge APCs but also subscription fees to libraries. Without an appropriate regulatory mechanism, the proliferation of predatory and double-dip journals on the internet poses a serious risk to legitimate journals like JAFES. Independent open-access publishers with online presence are subject to cyber-security issues, too, as JAFES was recently reminded.

Our website recently shifted to online hosting under the Public Knowledge Project (PKP), the original creator of the Open Journal Systems software. Beginning October 2016, the JAFES is no longer connected with Openjournalsystems.com.

In the website http://asean-endocrinejournal.org you will see quite a bit of change complementing the new brand and look of JAFES. Its article visualization is much improved according to the suggestion of the reviewers of the National Library of Medicine when they first reviewed JAFES for PubMed indexing. The website is also more responsive to a wider variety of devices that readers use to view content. We are excited to further develop the website with additional features to enhance readership not only for our member societies but the rest of the scientific community.

Indeed in the academic publishing world, independent open-access journals walk a challenging tightrope of maintaining integrity on top of sustaining operations. At the last Asia-Pacific Association of Medical Journal Editors (APAME) conference in Bangkok, Thailand, we bore witness to shared experiences of scholarly journals, regionally and globally, on issues of intellectual property and ethical publication, amid the unique risks posed by a world that is becoming more and more online.

JAFES continues to encourage research initiatives, to foster high quality publication standards, and to facilitate the sharing of scientific outputs from Southeast Asia to the world. Above all, we hold integrity as one of our core values, without which, JAFES will not survive and thrive. We deem safeguarding the intellectual property of the authors, reviewers and editors, who all contributed and continue to contribute to our issues, as critical to the mission. We count on the continuing support of all our readers.

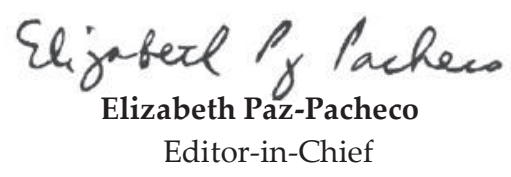

https://doi.org/10.15605/jafes.031.02.01 